\title{
THE CARDIODYNAMIC CHANGES IN THE AORTA AND LEFT VENTRICLE DUE TO STENOSIS OF THE AORTA
}

By LOUIS N. KATZ, ELAINE P. RALLI ${ }^{1}$ AND SHEO-NAN CHEER ${ }^{2}$

(From the Department of Physiology, Western Reserve University Medical School, Cleveland)

(Received for publication September 19, 1927)

INTRODUCTION

Our understanding of the dynamic changes which occur in stenosis of the aorta is inadequate in certain respects. Part of the deficiency can be attributed to the inaccurate methods used in recording pressure curves. This can be obviated by using optically recording manometers of high efficiency, particularly if the aortic and left ventricular pressures are recorded simultaneously. Curiously enough such records are lacking.

An analysis of the optically recorded pressure curve of the left ventricle during varying stages of stenosis of the aorta also gives accurate information of the effect on contraction produced by prevention of ejection and shortening to various extents. When the aorta is stenosed, the ventricle contracts more nearly isometrically, the closest approach occurring when the stenosis is complete. Thus complete stenosis, especially if it be produced in the pulmonary artery, offers an opportunity of studying the isometric contraction of the mammalian ventricle; a subject that has been neglected.

An analysis of the optically recorded aortic pressure curve is important also because it may help to account for the sudden interruption in the central pulse, which Feil and Katz (1) have shown is the anlage of the anacrotic wave in the radial pulse. No evidence is available to indicate whether the characteristic changes in the optical records of the subclavian pulse of patients with aortic stenosis also occur in the aortic curve in experimental stenosis of the aorta.

${ }^{1}$ Crile Research Fellow.

${ }^{2}$ Rockefeller Foundation Research Fellow from Peking Union Medical College. 


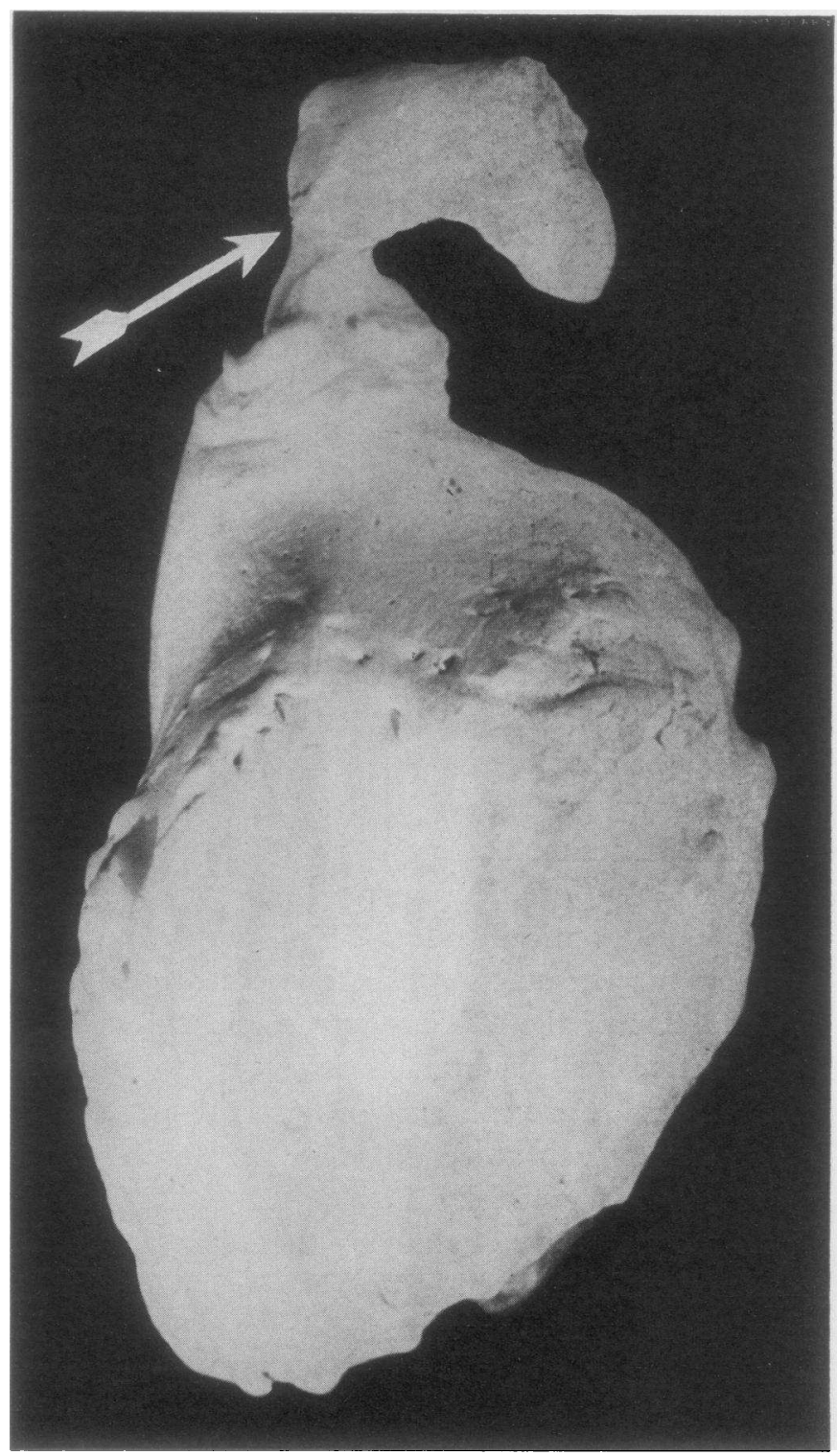

Fig. 1. A Cast of the Interior of the Left Ventricle and Aorta of a Dog, Made Immediately after Death (Posterior View) is Reproduced to Show the Location of the Constriction (Indicated by an Arrow) and Its Hour-glass Shape

We are indebted to Dr. H. Goldblatt for making the cast and to Prof. T. W. Todd and his staff for the photograph. 
In the present report these matters will be discussed on the basis of optically recorded pressure curve simultaneously obtained from the aorta and left ventricle during various stages of stenosis of the aorta.

\section{METHODS}

The pressure changes were registered by optically recording manometers (Wiggers and Baker (2)), using the double slit lamp of Katz and Baker (3) to avoid parallax between the two curves. The pressure in the two chambers at any given moment was thus recorded in exactly the same vertical plane. The dogs were anesthetized with morphine and sodium barbitol, injected intravenously. The method of exposing the heart and inserting the manometers was the one customarily used in this laboratory. The various degrees of stenosis were produced by tightening a ligature around the aorta, using a specially designed screw arrangement for this purpose. The ligature was placed about $1 \mathrm{~cm}$. or less above the free margin of the semilunar valves, the location being confirmed at autopsy. The constriction produced in this fashion was hour-glass in shape, as can be seen in the photograph (fig. 1, indicated by an arrow) of a plaster cast made immediately after the death of one of the animals. The aortic manometer was inserted through the left subclavian artery so that the end of its cannula was in the aorta about 1 $\mathrm{cm}$. distal to the neck of the constriction.

The experiments were made under various conditions of arterial resistance, venous return and heart rate. The amount of alveolar $\mathrm{CO}_{2}$ was maintained constant during each experiment. The vagi were cut in most cases; in a few, however, they were left intact.

\section{RESULTS}

The changes produced by stenosis of the aorta present a complicated picture because the effect of the primary changes are counterbalanced (or enhanced) by compensatory mechanisms. These compensatory mechanisms appear quickly and tend to persist as long as the stenosis is present. Experimental stenosis, as carried out in this research, increases the coronary flow and thus has little if any effect, provided the $\cdot$ cardiac nutrition is adequate to start with. In several animals the effect of impairment in cardiac nutrition in this condition was determined by analyzing the changes which occur in the right ventricle when the pulmonary artery was stenosed, a stenosis in this location leads to a decrease in coronary flow.

The mechanical compensatory mechanisms are probably of the same nature in the acute experiments as in the clinical cases. The 
short stretch of aorta between the valves and the constriction introduces no significant capacity factor which could prevent retention of blood within the ventricles.

In other respects the experiments are different from the clinical condition of aortic stenosis. For example, ventricular hypertrophy, aortic insufficiency and myocardial involvement which usually complicate the clinical case are absent in these acute experiments. Our object was not to reproduce all the mechanisms which appear in clinical cases of aortic stenosis, but rather to evaluate the primary dynamic changes in stenosis of the aorta, to see how they are modified by concurrent changes which the associated increase in diastolic stretch produces, and to determine the further modifications which nutritional impairment might give rise to. Such an analytical method is a necessary step in obtaining a clearer idea of the manner in which the clinical picture is produced, but it is only the first step.

\section{A comparison of the changes in the left ventricular pressure curve with those occurring in the aortic}

The fact that the aorta and left ventricle are in free communication during ejection would lead one to expect that during this period the contour of the aortic and left ventricular curves would be the same. The control curves (figs. $2 A, 3 A$ and $6 A$ ), show such similarity during ejection, that is to say, from the time the pressure in the aorta begins to rise until the incisuric drop takes place. As a matter of fact, it became clear to us that when this similarity was not present in control records, for example, in segment $A$ of figure 8, some artefact had been introduced depending on the placement of the ventricular cannula opening (Wiggers (4)). Such ventricular curves were discarded in this analysis.

When the aorta was stenosed the similarity of the curves during the ejection phase disappeared, the disparity increasing as the stenosis was increased; compare, for example, the portion of the pressure curves between the rise of the aortic pressure and the incisura in segments $B, C$, with the corresponding portion of the curves in segments $A$ of figures 2,3 and 6 . It will be seen that although the amplitude of the aortic curve decreases, the amplitude of the ventricular curve increases; and that although the gradient of the rise of 


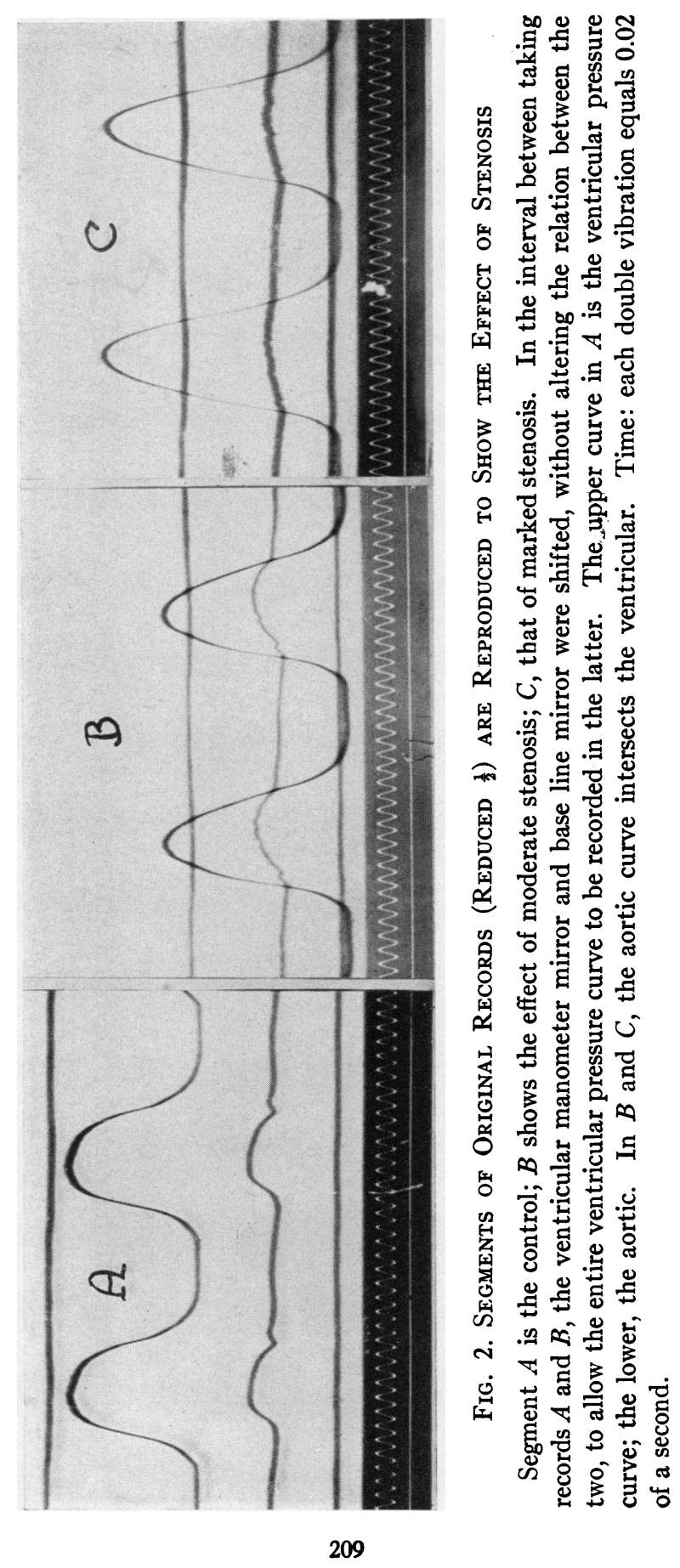




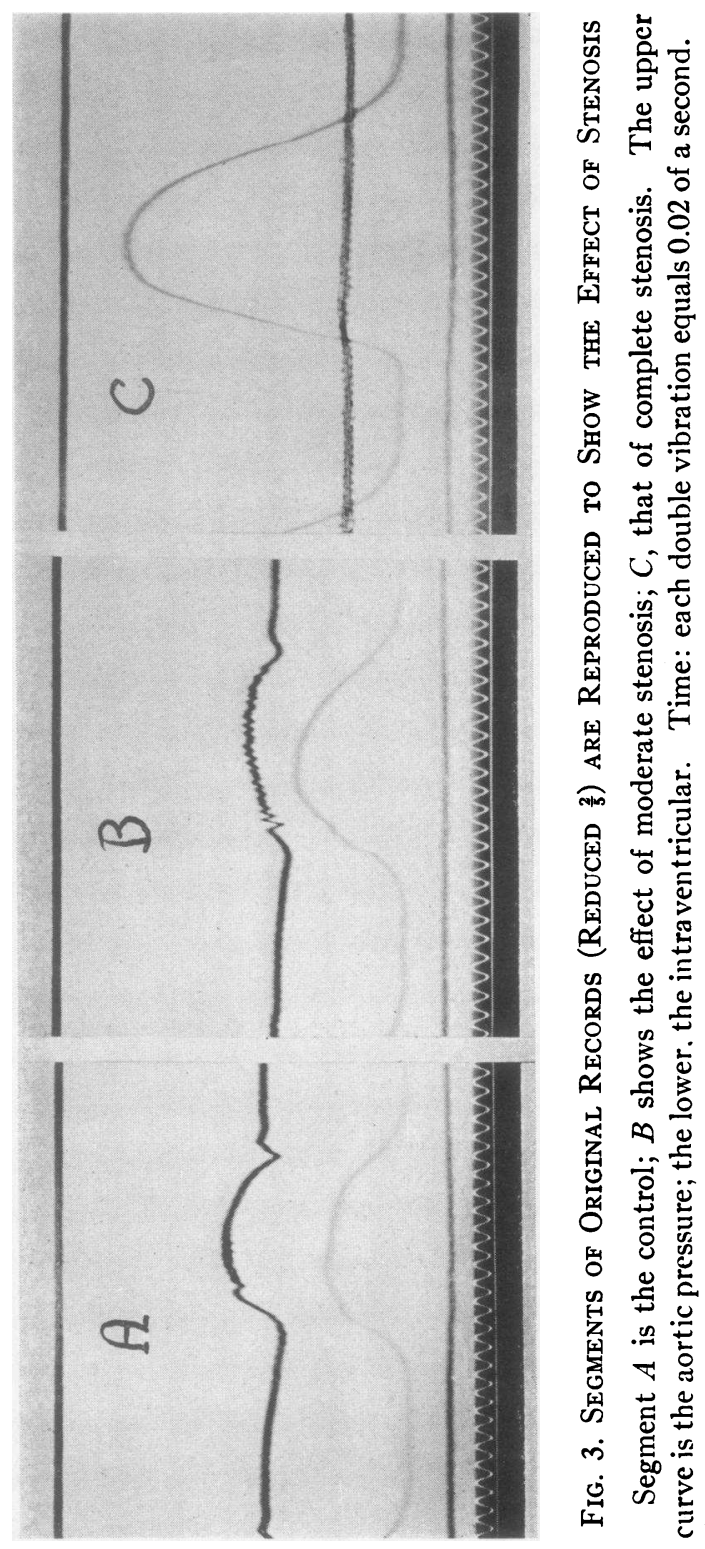


pressure in the aortic curve becomes more gradual, it becomes steeper in the ventricle. The location of the peak is also different in the two curves. The ventricular curve is free from the vibrations which appear during systole in the aortic curve, and there is no suggestion of a vibration equivalent to the anacrotic incisura present in the latter. These last two differences are not attributable to a less sensitive recording membrane on the ventricular manometer, as the difference in sensitivity of the two recording membranes was small and in several instances practically absent. ${ }^{3}$

The disappearance in the similarity of the basic form of the two pressure curves during ejection when the aorta is stenosed arises from the fact that the two chambers are no longer in free communication while blood is being ejected. The steeper and larger rise in ventricular pressure during this period, and the slower and smaller rise in aortic pressure are due to the decrease in the rate of conversion of potential mechanical energy in the ventricle to kinetic energy of flow. The development of tension in the ventricle is thus facilitated while the stretch of the arterial wall beyond the constriction is retarded. When the stenosis is complete, as in segment $C$ of figure 3, no external work is done, except for pumping blood through the coronary arteries; practically all the effort is static, that is to say, is used in raising the pressure in the ventricle and its contents to a certain level for a certain time period. In complete stenosis of the pulmonary artery, all the effort of the right ventricle is static in this sense; if the ventricular volume were known, the total mechanical energy, so liberated, could be calculated and its variation with altered diastolic stretch and nutritional condition estimated.

The detailed description of changes in the intraventricular pressure curve

Stenosis of the aorta (or pulmonary artery) caused an increase in the area enclosed beneath the pressure-time curve of the left (or right) ventricle. This increase resulted from increasing the height of the curve, its duration and the steepness of the ascending and descending

${ }^{3}$ The anacrotic jog present in the ventricular record of figure $8 B$ is an artefact which is more pronounced in the control record, segment $A$. It is, therefore, to be disregarded. 
limbs. These changes in contour are seen in figures 2 and 3 , and in the superimposed curves of figure $4 .{ }^{4}$

The maximum pressure attained by the ventricle increased progressively as the degree of stenosis was increased, reaching values of 250 to $325 \mathrm{~mm}$. of mercury in complete occlusion of the aorta, a three

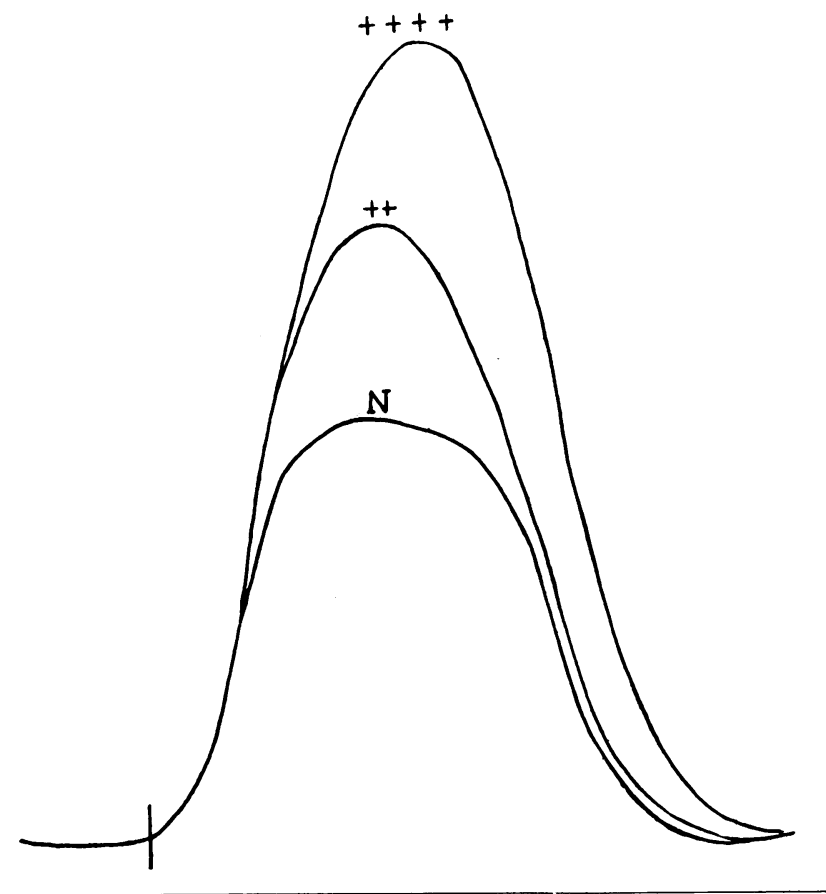

Fig. 4. Superimposed Left Ventricular Curves (about Natural Size) Are Reproduced to Show the Effect of Stenosis of the Aorta on the Pressure Changes in This Chamber

The curves are superimposed at the onset of the pressure rise, ignoring differences in initial tension. $N$ is the normal record; ++ and ++++ , two stages of stenosis of the aorta. The details are described in the text.

to five-fold augmentation above control values (fig. $3 A$ and $C$ and fig. 6 $A$ and $D$ ). These changes agree very closely with those described by de Heer (5).

${ }^{4}$ The use of a magnifying lens is advised to make the changes in gradient more distinct. 
The rounded arch-shaped summit of the normal pressure curve disappeared and was replaced by a summit which progressively became more peaked as the contraction of the ventricle became more isometric. The time at which the peak was reached was variable. The progressively later occurrence of the peak, which de Heer's (5) curves show, and which might lead to the belief that its position in the ventricular curve was the same as in the aortic, did not occur in most of our records. In many cases the relation of the peak to the rise of pressure remained unchanged, in others (fig. 6), it occurred earlier. Occasionally it shifted in one and then in the other direction in the same experiment as the degree of stenosis was augmented. Its location is doubtlessly dependent on the manner in which the contraction and relaxation processes in different fractions of the ventricle summate.

The usual effect of the stenosis was to prolong the duration of the curve (figs. 2, 3 and 4). A similar difference in duration was noted by Fulton (6), between skeletal muscle allowed to shorten and the same muscle contracting isometrically. While Fulton could ascribe this change in his experiments to the prevention of shortening, in our experiments it might be due to the increase in initial tension (Wiggers and Katz (7), and Wiggers (8)), which accompanies the stenosis (fig. 3). The increase in initial tension (or diastolic stretch) was always present. This agrees with the observation of Straub (9) and with the finding of an increase in the diastolic volume by Straub (9) and de Heer (5) in similar types of stenosis. The inability of Lüderitz (10) and de Heer (5) to note an increase in initial tension can be ascribed to their failure to record a base line.

In mild stenosis the change in initial tension may be so small as not to be readily measurable. The changes were made more distinct by accurately retracing the curves on coördinate paper, after magnifying them four-fold in a reflectoscope, so that their base lines coincided.

That the increase in diastolic stretch is not the sole cause for the prolongation of the curve is shown in continuous records taken immediately after the stenosis was made. A prolongation of the curve was present in the beat following the production of stenosis before any appreciable increase in diastolic stretch occurred.

The interaction of the primary effect of stenosis and of the associated change in diastolic stretch may be made clearer by describing a typical 
experiment (fig. 5). In this figure the normal pressure curve of the right ventricle $(N)$ and the first and second beat (1 and 2) following immediately after the production of stenosis in the pulmonary artery, are superimposed. (Beats $L$ and $S L$ will be referred to later.) The curves are superimposed at the onset of the pressure rise so that their

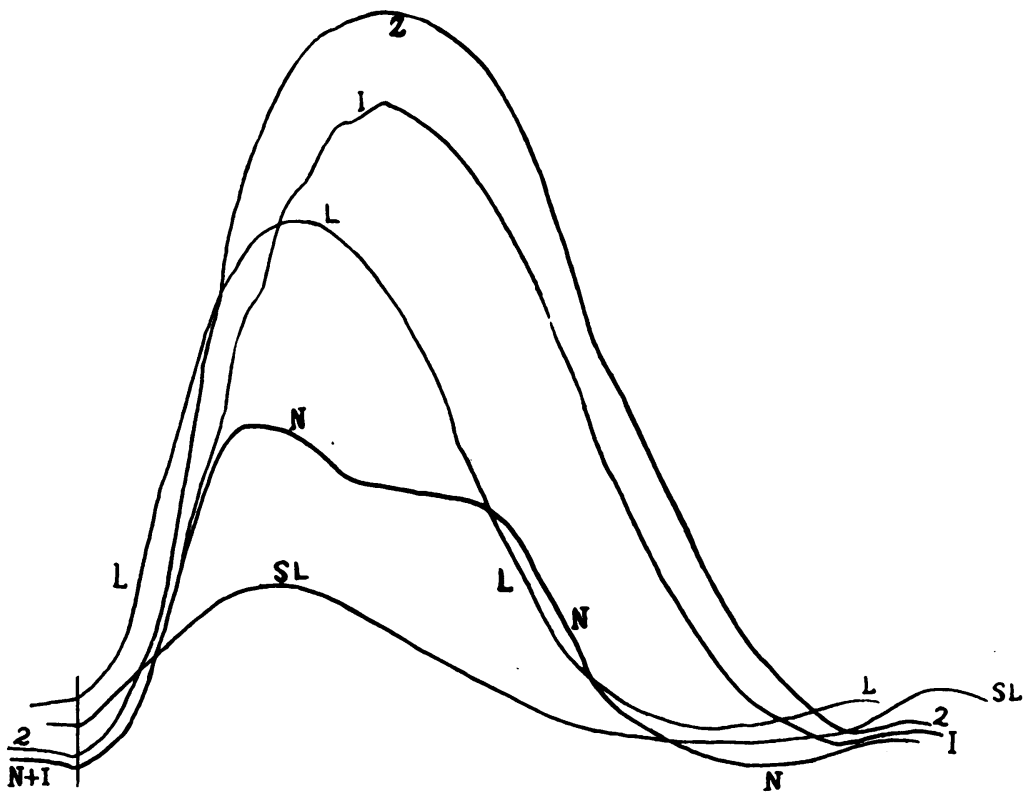

Fig. 5. Superimposed Successive Right Ventricular Pressure Curves (about 1 $\frac{1}{2}$ Natural Size) Are Reproduced to Show the Effect of Complete Pulmonary Stenosis

The curves are superimposed at the onset of the pressure rise so their base lines coincide. $N$ is the control; 1 , the curve of a cycle during the systole of which complete stenosis was made; 2 , next beat; $L$, about the twentieth beat following; $S L$, about the thirty-fifth beat. The details are described in the text.

base lines coincide. The stenosis in this particular case was complete and was made quickly during the systole of beat 1 , as shown by the oscillation on the ascent of this curve. The pressure immediately rises to a higher level, the summit becomes peaked, and the duration of the curve increases, and yet the initial tension is the same as before 
(compare beats $N$ and 1). Such experiments show that the introduction of isometric conditions in itself increases the height of the curve, prolongs it and makes it more peaked. The rise of initial tension which occurs soon after (compare beats 1 and 2) augments these changes.

Both of these curves ( 1 and 2) show the contour of a completely isometric contraction (or as nearly isometric as possible) in the mammalian ventricle, as compared with the normal after-loaded contraction $(N)$. A comparison of the two beats (1 and 2) shows further that an increase in the initial tension of the ventricle causes an increase in the energy output in an isometrically contracting heart-a relation also true of isometrically contracting skeletal muscle. This is indicated by the increase in the area beneath the pressure-time curve of the ventricle, which occurs in spite of the larger volume of the heart.

The continued presence of stenosis leads in this experiment to diminution in coronary flow and consequent impairment of nutrition. The initial tension rises still more in the beats following beat 2 , but because of the impairment in nutrition, the curves become smaller in height and shorter in duration, although still showing the characteristic peaked contour, for example beat $L$, which is about the twentieth beat after the appearance of stenosis. Finally, as the impairment in nutrition continues, the amplitude and duration become less than normal, for example beat $S L$ which is about the thirty-fifth beat after the appearance of stenosis. At this time the initial tension also becomes lower. Similar changes, attributable to nutritional impairment were noted in the other experiments made on the right heart.

Occasionally similar nutritional effects occurred in the left ventricle after complete aortic stenoses had been made and released several times in the same animal before beginning the experiment. Figure 6 is an example of such an experiment. The diastolic pressure was very low in this animal; the dilation of the ventricles persisted after the stenosis (the fifth one made) was released, and in a few minutes the heart ceased contracting. Although the height and contour changes of the ventricular curve are typical, its duration is not prolonged but abbreviated by the stenosis. This substantiates the fact emphasized previously by one of us (L. N. K. (11)) that occassionally one effect of failure is an abbreviation of the contraction time of the heart. 


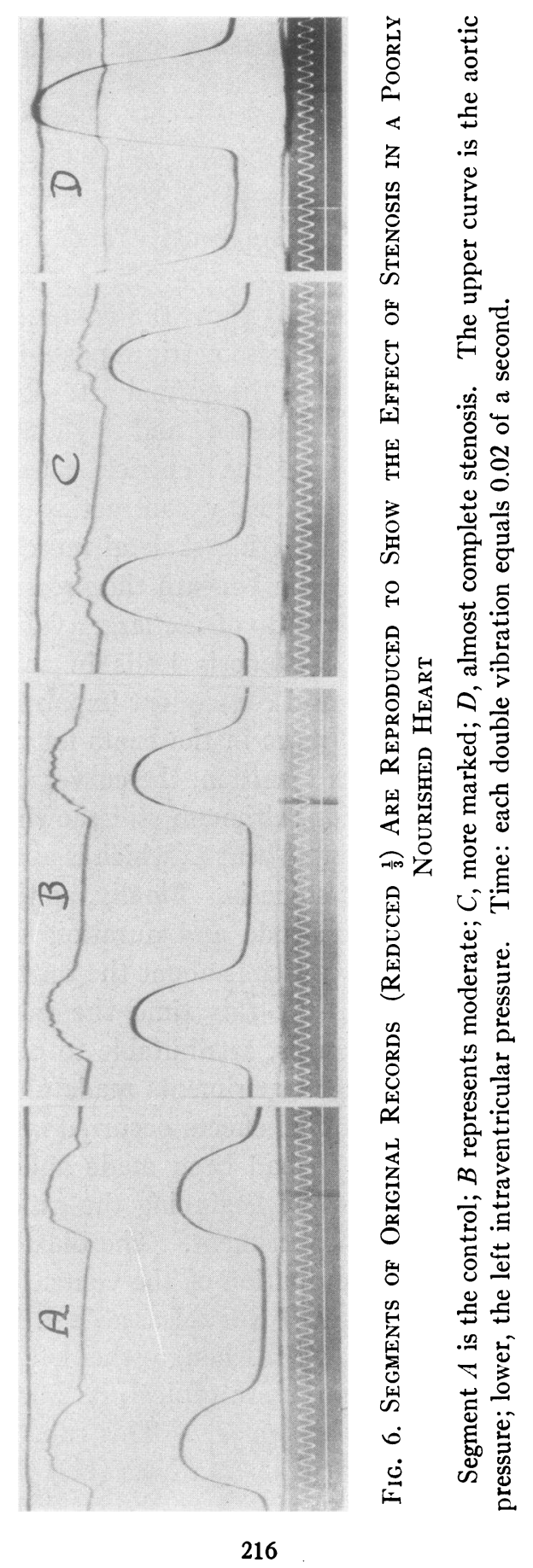




\section{The detailed description of changes in the contour of the aortic pressure curve}

A. Pressure levels. Before discussing the more significant changes in contour it is well to summarize the changes observed in the pressure levels in the aorta following stenosis. This summary is based on an analysis of the calibrated optically recorded aortic pressure records.

In agreement with previous investigators, we found that the diastolic pressure fell in most instances. The fall was particularly noticeable in the beats immedately after the induction of stenosis but was present in later beats also (figs. 2, 3, 6 and 7). In a few cases of mild stenosis, however, we found in agreement with Lüderitz (10), that a rise occurred, or the level did not change. The systolic pressure also fell; as a rule more markedly than the diastolic, so that the pulse pressure also decreased (figs. 2, 3, 6 and 7). In a few cases with mild stenosis and vigorous heart action, a temporary slight rise in systolic pressure and pulse pressure was present (fig. 8). The mean blood pressure was not measured directly, but the changes in the other pressures indicate that it usually fell. This is in accord with the direct observations of MacCallum (12), de Heer (5) and Straub (9).

The lowering of the aortic pressure levels and the decrease in pulse pressure is due to the diminution in systolic discharge and minute output of the heart, a decrease noted by de Heer (5) and Straub (9). The cause is obviously the utilization of more of the mechanical energy of the ventricle to overcome the added obstructions caused by the stenosis; consequently less is left for kinetic energy of flow. ${ }^{5}$

Two compensatory mechanisms come into operation at once however. In the first place, the fall in aortic pressure reduces the augmented resistance against which the heart works and so allows utilization of more mechanical energy for kinetic energy of flow. In the second place, the retention of blood in the ventricle, by virtue of the resulting increase in diastole stretch, causes an augmentation in the chemical energy exchange, shown by an increased $\mathrm{O}_{2}$ consumption, (Starling and Visscher (13)). The total amount of available mechani-

\footnotetext{
${ }^{5}$ The effect of a reduced return of blood to the left ventricle might be an added factor in the clinical case. The increase in coronary flow which accompanies the diminution in peripheral flow would minimize such an effect in these experiments.
} 
cal energy is thereby increased, assuming of course that the efficiency of the transformation is practically unchanged. In mild stenosis the effect of the increase in diastolic stretch may be large enough to counterbalance the primary effect of the constriction and cause a temporary rise in the pressure levels.

B. The basic form and the superimposed finer changes. Stenosis not only causes a lowering of the pressure levels in the aorta but also alters the fundamental form of the pressure-time curve. This consists in the ascent becoming more gradual and protracted and in the occurrence of the peak later in systole. Certain finer modifications also appear, namely, fine systolic vibrations preceded by a large decisive downward vibration, located on the early portion of the ascending limb of the curve. The incisura at the end of ejection, becomes less marked, and its obscurity is often increased by vibrations. The small after-vibration, which usually follows the incisura in the normal curve, tends to disappear. These changes are seen in figures $2,3,6,7$ and 8 .

The presence of these changes in the aortic curve, which resemble those optically recorded in the subclavian pulse of clinical cases of aortic stenosis, precludes the idea that they arise in transmission from the aorta to the subclavian artery. They are absent from the ventricular pressure curve and so must arise de novo at or just beyond the constriction.

All of the changes become more noticeable, up to a certain point, as the stenosis is increased. The decline in the gradient of the ascent, for example, progressively becomes more noticeable (figs. 2, 6 and 7); in mild stenoses, where the systolic pressure rises, a steeper ascent is seen occasionally (fig. 8). The peak of the curve is another example; it tends to occur progressively later as the ascent becomes more gradual.

C. The systolic vibrations. These vibrations appear in the mildest grades of stenosis, even when the pulse amplitude is increased (fig. 8). In fact, they may be larger in such cases than in more marked stenosis. The vibrations are irregular in size and frequency (fig. $8 B$ and fig. $7 D$ ). The vibration frequency in this series ranged from 55 to 200 double vibrations per second; the range being somewhat less in a single beat. The vibrations do not coincide with the onset of ejection but appear after an interval of 0.02 to 0.04 of a second (figs. 2, 3, 6, 7 and 8). 

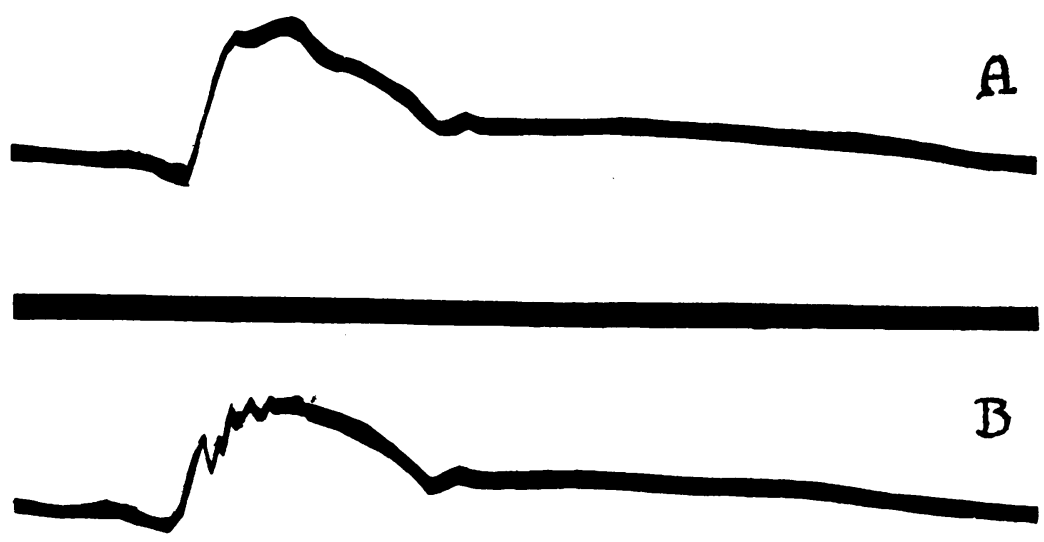

$\mathcal{B}$
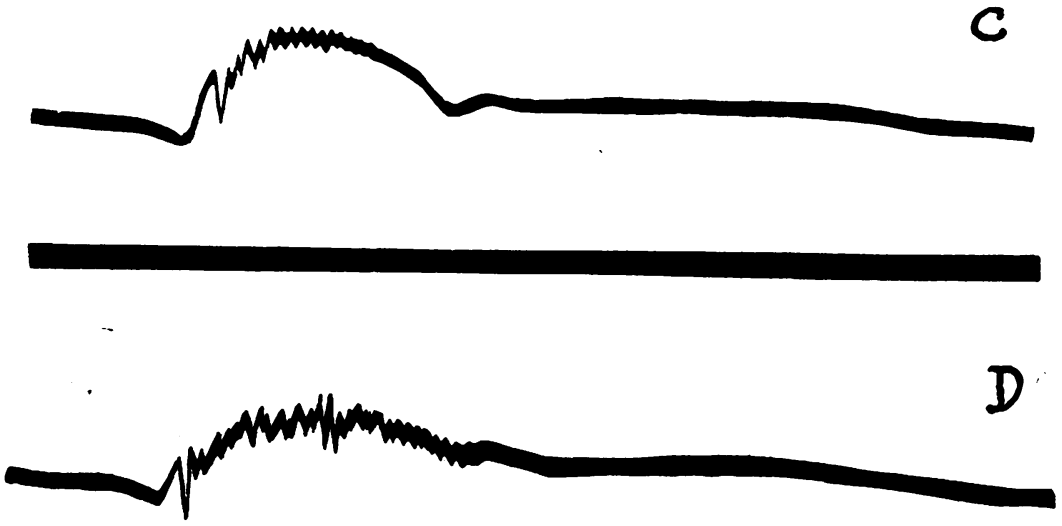

Fig. 7. Four Segments of Aortic Pressure Curves (about Natural Size) Are Presented to Show the Changes in Contour at Various Degrees of Stenosis of the Aorta

Segment $A$ is a normal record; segments $B, C, D$, successive increases in stenosis of the aorta, from mild to fairly marked. 
They sometimes end before the incisura, but often are visible in early diastole (fig. $8 \mathrm{C}$ and fig. $7 \mathrm{D}$ ). The duration of the vibration increases as the stenosis becomes more marked (figs. 7 and 8). The vibrations found in these animal experiments resemble those observed by Feil and Katz (1), as to the time of their appearance, their vibration frequency and their irregularity.

The manner in which these records were obtained precludes entertaining the idea that the delay in their onset and their persistence into diastole are due to differences in the rate at which the various

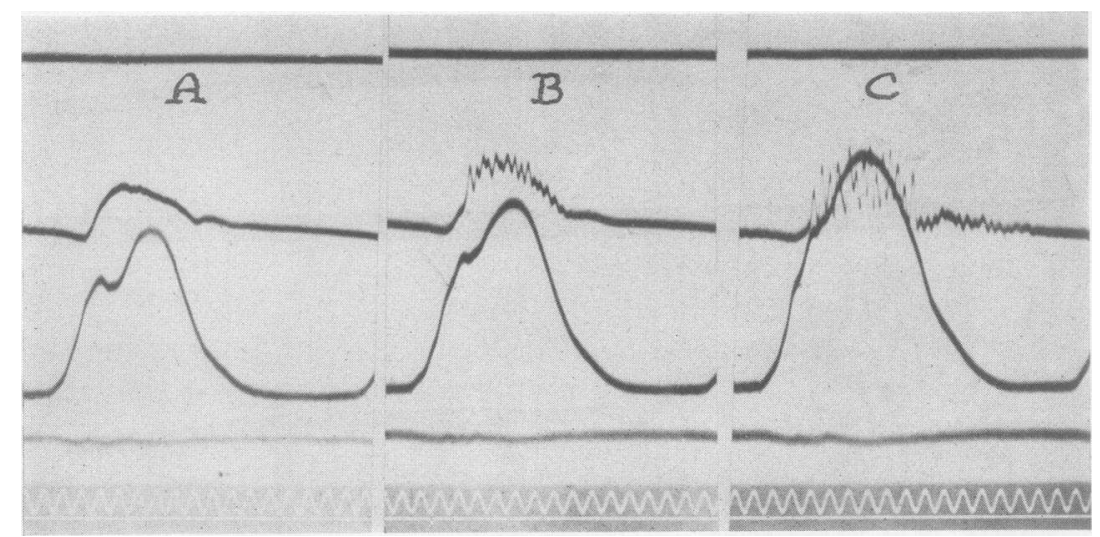

Fig. 8. Three Segments of Original Curves (about $\frac{1}{2}$ Normal Size) are Presented to Show the Effect of Mild Stenosis of the Aorta

Segment $A$ is a normal record; segments $B$ and $C$, two mild stages of stenosis. The upper curve is aortic pressure; the vibrations are enhanced by resonance effect. The lower curve is left ventricular pressure; the wave on the ascending limb is an artefact, as is also the summit which follows. This is indicated by the fact that in the normal curve (segment A) the contour of the ventricular curve does not resemble that of the aorta. Time: each double vibration equals 0.02 of a second.

types of pressure changes are transmitted to the recording membrane, inasmuch as the entire liquid recording medium was encased in a rigid tube and the distance from the stenosis to the rubber membrane was approximately $15 \mathrm{~cm}$. The sensitivity of the membrane which is relatively low for such a purpose, however, tends to diminish the amplitude of the vibrations, so that in certain cases, as in segments $B$ and $C$ of figure 2, they are barely discernible. In some cases, on the 
other hand, as in segments $B$ and $C$ of figure 8, resonance effects probably increase their amplitude. The vibration frequency of these manometers (about 200 double vibrations per second) tends furthermore, to distort the vibrations somewhat. The properties of the recording membrane employed, however, do not introduce any appreciable delay in their registration (Broemser (14)).

The vibrations are due to eddies and consequently more or less harmonic vibrations, produced by the axial stream flowing beyond the constriction. Their amplitude and vibration frequency are determined by the degree of the hour-glass distortion of the arterial wall, by the velocity with which blood flows past the constriction, and by the physical properties of the blood-filled elastic tube beyond. The delay in their onset is due to the inertia of the arterial system. This may also account in part for their persistence after ejection has ceased. The persistence may also be due to a backward movement of blood, which occurs during protodiastole (Frank (15)). While such explanations may account for the vibrations occurring immediately after ejection, they cannot explain those which appear later (fig. $8 \mathrm{C}$ ). The latter may be the result of the rapid emptying of the aorta proximal to the constriction after the semilunar valves are closed. It is evident that when ejection terminates the pressure in this portion must be considerably higher than in the rest of the aorta.

$D$. The sharp vibration on the ascending limb. The sharp vibration which is characteristic of stenosis, appears even in mild stenosis (fig. $8 \mathrm{~B}$ ), but is more distinct in moderate stenosis (figs. $2 B, 3 B$, and $6 B$ and fig. $7 B, C, D$. In more marked stenosis it again becomes less distinct (figs. $2 C$ and $6 C$ ). The vibration usually appears as a steep downward incisura followed by an equally steep rise; on rare occasions, in mild stenosis, it may start with a component directed upward (fig. 8). The normal aortic pressure curve is free of such a sharp vibration although occasionally, as in segment $A$ of figure 3, a slight vibration may be seen. This, when it occurs, is always close to the maximum pressure level in the aorta, whereas the vibration in aortic stenosis always occurs on the ascending limb. The position of the vibration varies as the degree of stenosis is changed. The changes which occur in the vibration during the early stages of stenosis can be followed best by analyzing the records shown in figure 7 . It 
will be seen that as the stenosis increases, the ascent preceding the vibration becomes less steep, its duration decreases and its height diminishes. In other words the vibration occurs progressively earlier and lower down on the limb as the stenosis becomes more marked. Actual computations based on fourfold magnification of these curves show that the level at which the vibration starts is 75 per cent lower in segment $C$ than in $B$, and 60 per cent lower in $D$ than in $C$. In segment $B$ it starts 0.02 of a second after the onset of ejection, whereas in $C$ and $D$ it starts sooner, namely 0.016 and 0.011 of a second after the onset of ejection, respectively. The vibration, at the same time becomes larger, has steeper gradients and a slightly shorter duration, that is to say, its duration in segment $B$ is 0.010 of a second, in $C$, 0.009 and in $D, 0.008$ of a second.

The fact that this vibration has a steeper gradient than the ascent preceding it, excludes the possibility of its being a reflected wave from the constriction or any other point. It must be a forced vibration, in the same sense that Frank (16) uses the term in calling the incisura of the normal pulse a forced vibration.

The "breaking of the wave front" hypothesis of Bramwell (17) to which he attributes certain anacrotic vibrations, cannot be the cause in aortic stenosis, as the wave front is less steep than normally and consequently such a phenomenon could not possibly occur in the short distance of $1 \mathrm{~cm}$. which separates the constriction from the opening of the manometer.

An explanation is offered which will rationally account for such a vibration. It is well-known that when a fluid stream is suddenly forced through a narrow opening into a larger tube, the stream becomes axial in the larger tube and tends to create a sudden sharp reduction in pressure in the marginal region. A similar phenomenon occurs in the aorta beyond the stenosis. The pull of this reduced pressure reacts on the wall of the aorta and sets up the vibration which we have desoribed. Obviously the greater the velocity of the axial stream, the more marked will be the reduction in the marginal pressure and hence, the larger will be the vibration set up. Such an increase in the velocity of the axial stream acompanies the narrowing of the constriction.

This anacootic vilbration is the anlage of the anacrotic interruption in the radial pulse, just as the incisura is the anlage of the dicrotic wave. 
TABLE 1

Effect of stemosis of the aorta on the duration of phases of cycle

\begin{tabular}{|c|c|c|c|c|c|c|}
\hline $\begin{array}{l}\text { Experiment } \\
\text { number }\end{array}$ & $\begin{array}{l}\text { Degree of } \\
\text { stenosis }\end{array}$ & $\begin{array}{c}\text { Duration of } \\
\text { isometric } \\
\text { contraction } \\
\text { phase }\end{array}$ & $\begin{array}{c}\text { Duration of } \\
\text { ejection } \\
\text { phase }\end{array}$ & $\begin{array}{l}\text { Duration of } \\
\text { total systole }\end{array}$ & $\begin{array}{l}\text { Duration of } \\
\text { preceding } \\
\text { diastole }\end{array}$ & $\begin{array}{l}\text { Duration of } \\
\text { cycle }\end{array}$ \\
\hline & & seconds & seconds & seconds & seconds & seconds \\
\hline $70-1^{*}$ & 0 & 0.052 & 0.107 & 0.159 & 0.167 & 0.326 \\
\hline 4 & ++ & 0.038 & 0.120 & 0.158 & 0.165 & 0.323 \\
\hline 2 & ++++ & 0.038 & 0.140 & 0.178 & 0.142 & 0.320 \\
\hline $70-21^{*}$ & 0 & 0.032 & 0.150 & 0.182 & 0.258 & 0.440 \\
\hline 22 & ++ & 0.030 & 0.140 & 0.170 & 0.244 & 0.414 \\
\hline 23 & $++t+$ & 0.023 & 0.132 & 0.155 & 0.235 & 0.390 \\
\hline $74-1^{*}$ & 0 & 0.039 & 0.093 & 0.132 & 0.130 & 0.262 \\
\hline 2 & \pm & 0.037 & 0.101 & 0.138 & 0.160 & 0.298 \\
\hline 3 & + & 0.038 & C.102 & 0.140 & 0.160 & 0.300 \\
\hline 4 & ++ & 0.035 & 0.113 & 0.148 & 0.147 & 0.295 \\
\hline 5 & 0 & 0.035 & 0.095 & 0.130 & 0.195 & 0.325 \\
\hline 7 & \pm & 0.037 & 0.130 & 0.167 & 0.178 & 0.345 \\
\hline 8 & ++ & 0.038 & 0.117 & 0.155 & 0.158 & 0.303 \\
\hline 9 & +++ & 0.038 & 0.122 & 0.160 & 0.163 & 0.323 \\
\hline $74-24 \dagger$ & 0 & 0.043 & 0.095 & 0.138 & 0.202 & 0.340 \\
\hline 25 & + & 0.040 & 0.108 & 0.148 & 0.205 & 0.353 \\
\hline 26 & ++ & 0.040 & 0.110 & 0.150 & 0.188 & 0.338 \\
\hline $74-39 \ddagger$ & 0 & 0.038 & 0.130 & 0.168 & 0.440 & 0.608 \\
\hline 40 & + & 0.040 & 0.165 & 0.205 & 0.412 & 0.617 \\
\hline 41 & ++ & 0.040 & 0.142 & 0.182 & 0.383 & 0.565 \\
\hline $75-1 \dagger$ & 0 & 0.050 & 0.090 & 0.140 & 0.145 & 0.285 \\
\hline 2 & + & 0.048 & 0.095 & 0.143 & 0.145 & 0.288 \\
\hline 3 & ++ & 0.053 & 0.095 & 0.148 & 0.143 & 0.291 \\
\hline 5 & +++ & 0.040 & 0.107 & 0.147 & 0.133 & 0.280 \\
\hline 75-10† & 0 & 0.028 & 0.124 & 0.152 & 0.370 & 0.522 \\
\hline 12 & + & 0.030 & 0.130 & 0.160 & 0.370 & 0.530 \\
\hline 13 & ++ & 0.032 & 0.133 & 0.165 & 0.380 & 0.545 \\
\hline 15 & ++++ & 0.032 & 0.139 & 0.172 & 0.403 & 0.575 \\
\hline $76-1 \dagger$ & 0 & 0.058 & 0.168 & 0.226 & 0.215 & 0.441 \\
\hline 3 & ++ & 0.055 & 0.200 & 0.255 & 0.168 & 0.423 \\
\hline
\end{tabular}

* Vagi intact.

+ Vagi cut.

$\ddagger$ Vagi cut. During action of pilocarpin. 
TABLE 1-Concluded

\begin{tabular}{|c|c|c|c|c|c|c|}
\hline $\begin{array}{c}\text { Experiment } \\
\text { number" }\end{array}$ & $\begin{array}{l}\text { Degree of } \\
\text { stenosis }\end{array}$ & $\begin{array}{l}\text { Duration of } \\
\text { isometric } \\
\text { contraction } \\
\text { phase }\end{array}$ & $\begin{array}{c}\text { Duration of } \\
\text { ejection } \\
\text { phase }\end{array}$ & $\begin{array}{l}\text { Duration of } \\
\text { total systole }\end{array}$ & $\begin{array}{c}\text { Duration of } \\
\text { preceding } \\
\text { diastole }\end{array}$ & $\begin{array}{l}\text { Duration of } \\
\text { cycle }\end{array}$ \\
\hline & & seconds & seconds & seconds & seconds & seconds \\
\hline $76-9 \dagger$ & 0 & 0.042 & 0.160 & 0.202 & 0.215 & 0.417 \\
\hline 11 & ++ & 0.035 & 0.190 & 0.225 & 0.180 & 0.405 \\
\hline 80-1† & 0 & 0.032 & 0.105 & 0.137 & 0.215 & 0.352 \\
\hline 2 & + & 0.032 & 0.113 & 0.145 & 0.220 & 0.363 \\
\hline 3 & +++ & 0.040 & 0.130 & 0.170 & 0.193 & 0.363 \\
\hline $80-5 \dagger$ & 0 & 0.032 & 0.103 & 0.135 & 0.230 & 0.365 \\
\hline 6 & + & 0.032 & 0.108 & 0.140 & 0.205 & 0.345 \\
\hline 7 & +++ & 0.032 & 0.130 & 0.162 & 0.195 & 0.357 \\
\hline $80-17 \S$ & & & & & & \\
\hline Beat 2 & 0 & 0.023 & 0.100 & 0.123 & 0.205 & 0.328 \\
\hline Beat 4 & + & 0.023 & 0.100 & 0.123 & 0.200 & 0.323 \\
\hline Beat 6 & ++ & 0.030 & 0.103 & 0.133 & 0.192 & 0.325 \\
\hline Beat 9 & +++ & 0.035 & 0.110 & 0.145 & 0.185 & 0.330 \\
\hline
\end{tabular}

$\$$ Vagi cut. Consecutive beats in case of progressively increasing stenosis.

The changes in duration of the phases of the cardiac cycle

In the course of this investigation a systematic analysis was made of the duration of the phases of systole and the changes in cycle length, with the idea of comparing them with changes observed in clinical cases. The data of typical experiments are given in table 1 .

The results may be succinctly stated as follows: The cycle shortened slightly in most cases as the stenosis increased, regardless of whether the vagi were cut (last column). This is contrary to clinical experience. The abbreviation was not always present; in some cases practically no change occurred, (for example, in experiments 70,$1 ; 75,1$ to $5 ; 80,17$ ) in others a lengthening was noted (for example, in experiment 75,10 to 15 ). The part played by such factors as reflexes, and by mechanical stimulation of nerves caused by the ligature cannot be ascertained at present.

Total systole ${ }^{6}$ lengthened, as a rule (column 5 , table 1 ). On rare

${ }^{6}$ Only those beats in which the end of ejection could be accurately determined were measured. 
occasions when heart failure was imminent, it shortened (for example, in experiments 70,21 to 23). The lengthening of total systole was due to an increased duration of ejection and often occurred in spite of an unchanged or even an abbreviated isometric contraction phase (columns 3, 4 and 5, table 1). The lengthening of ejection and total systole was most noticeable in marked degrees of stenosis. In mild stenosis it was sometimes absent (for example, in experiments 80,17 ; beats 2 and 4). The changes in the systolic phases were similar to those noted in clinical cases (Katz and Feil (18)), except that the consistent lengthening of the isometric period was absent in the animal experiments. They agree more closely with those made by Lüderitz (10) and by de Heer (5) on animals.

The lengthening of systole and ejection is in part due to the increase in diastolic stretch (Wiggers and Katz (7)) accompanying the stenosis but probably also to the prevention of shortening (Fulton (6)). The slight changes in the isometric period are the result of the opposing action of the greater diastolic stretch and greater arterial resistance; the former tending to abbreviate and the latter to prolong this period (Katz and Feil (18)).

\section{SUMMARY}

1. An analysis was made of the effects produced by stenosis of the aorta $1 \mathrm{~cm}$. above the free margin of the semilunar valves, based on optical pressure curves recorded simultaneously from the aorta and left ventricle.

2. The condition thus produced allows a better opportunity to evaluate the primary effects of the stenosis and the immediate mechanical compensatory mechanisms than the clinical case.

3. The contour of the left ventricular curve is altered by stenosis of the aorta. Its height is increased and the summit becomes more peaked as the contraction becomes more isometric. At the same time, its duration increases and the ascent and descent are steeper. No, fine vibrations are superimposed.

4. The changes in the pressure curve are shown to be partly the result of the constriction itself which decreases the conversion of the potential mechanical energy to kinetic energy of flow and partly the result of the increase in the diastolic stretch of the ventricle. 
5. The effect of impairing the mutrition of the heart was analyzed by repeating the experiments on the right heart. This causes: an abbreviation in duration and a decrease in the height of the pressuretime curve in spite of the: opposing effect of the stenosis itself, and of the increased diastolic stretch.

6. The pressure curve of a completly isometric contraction of the right ventricle is reproduced.

7. The normal parallelism in the fundamental contour of the aortic and left ventricular curves during the ejection period disappears when a stenosis is created. The amplitude of the curves; as well as the gradients of the ascent, change in opposite diredions, and the peaks no longer coincide in time.

8. The changes in the aortic pressure curve produced by the stenosis are summarized as follows:

a. Decreased pulse amplitude.

b. Lowered level of the pressures.

c. Prolongation of the ejection period.

d. Diminished gradient of the ascent.

$e$. Less decisive incisura with obscuring of its after-vibration.

$f$. Superimposition of systolic (and early diastolic) vibrations on the curve.

g. Appearance of a sharp vibration low down on the ascent of the curve.

9. The resemblance of the aortic curve to optical curves recorded from the subclavian artery in clinical cases of aortic stenosis is evident.

10. The delay in the onset of the systolic vibrations, as well as their persistence into diastole, is pointed out.

11. The sharp vibration on the ascent, which changes its position with different degrees of stenosis; is analyzed and evidence is given to show that it is a forced vibration.

12. It is suggested that this vibration is created by the suction action of the suddenly produced swift axial stream beyomet the constriction.

13. The importance of this vibration as the anlage of the anacrotic wave in the radial pulse is again emphasized. 


\section{BIBLIOGRAPHY}

1. Feil, H. S., and Katz, L. N., Amer. Heart Journ., 1926, ii, 12. The Transformation of the Central into the Peripheral Pulse in Patients with Aortic Stenosis.

2. Wiggers, C. J., and Baker W. R., Journ. Lab. and Clin. Med., 1924, x, 54. A New Universal Optical Manometer.

3. Katz, L. N., and Baker, W. R., Journ. Lab. and Clin. Med., 1924, x, 47. An Adjustable Double-Slit Lamp for Use in Multiple Optical Registrations.

4. Wiggers, C. J., Personal communication.

5. de Heer, J. L., Arch. f. d. ges. Physiol., 1912, cxlviii, 1. Die Dynamik des Säugetierherzens im Krieslauf in der Norm, bei Aortenstenose und nach Strophantin.

6. Fulton, J. F., Amer. Journ. Physiol., 1925, lxxv, 235. The Influence of Shortening on the Size of the Action Current and the Duration of the Mechanical Response of Skeletal Muscle.

7. Wiggers, C. J., and Katz, L. N., Amer. Journ. Physiol., 1922, lviii, $439 . \quad$ The Contour of the Ventricular Volume Curves under Different Conditions.

8. Wiggers, C. J., Circulation in Health and Disease, Lea and Febiger, Philadelphia, 1923, p. 94-104.

9. Straub, H., Deutsch. Arch. f. Klin. Med. 1917, cxxii, 156. Zur Dynamik der Klappenfehler des Linken Herzens.

10. Lüderitz, C., Zeitschr. f. Klin. Med., 1892, xx, 374. Versuche über den Ablauf des Blutdruckes bei Aortenstenose.

11. Katz, L. N., Amer. Journ. Physiol., 1927, lxxx, 470. Observations on the Dynamics of Ventricular Contraction in the Heart-Lung Preparation.

12. MacCallum, W. G., Bull. Johns Hopkins Hosp., 1906, xvii, 251. On the Teaching of Pathological Physiology.

13. Starling, E. H., and Visscher, M. B., Journ. Physiol., 1927, 1xii, 243. The Regulation of the Energy Output of the Heart.

14. Broemser, P., Habilitationschrift aus dem Kgl. Physiol. Inst. zu München, 1918. Die Bedeutung der Lehre von den erzwungnen Schwingungen in der Physiologie.

15. Frank, O., Zeitschr. f. Biol., 1895, xxxii, 370. Zur Dynamik des Herzmuskels.

16. Frank, O., Sitzungsberichte d. Gesellschaft f. Morphol. u. Physiol. in München, 1926, xxxvii, Jahrgang, 33. Das Altern der Arterien.

17. Bramwell, J. C., Heart, 1925, xii, 23. The Change in Form of the Pulse Wave in the Course of Transmission.

18. Katz, L. N., and Feil, H. S., Heart, 1925, xii, 171. Clinical Observations on the Dynamics of Ventricular Systole. III. Aortic Stenosis and Aortic Insufficiency. 